\title{
The KwaZulu-Natal School Library Policy and its feasibility for implementation in the Province
}

\author{
Mariana du Toit ${ }^{1}$ \\ Coordinator: Research and Development, Mobile Library Project, \\ South African Primary Education Support Initiative (SAPESI) \\ dd34@mweb.co.za \\ Christine Stilwell ${ }^{2}$ \\ Information Studies Programme, School of Social Sciences, College of Humanities, \\ University of KwaZulu-Natal, Pietermaritzburg, South Africa \\ stilwell@ukzn.ac.za
}

Received: 2 November 2012

Accepted: 2 February 2013

\begin{abstract}
This article reports on research on the KwaZulu-Natal School Library Policy, its implementation strategy and feasibility for implementation in the province of KwaZulu-Natal. The article is the base research article which draws on a larger study which was undertaken for a doctorate. The first research objective of the study was to analyse and critically assess the KwaZulu-Natal School Library Policy document and its implementation strategy. Other objectives focused on the key elements of the provincial policy and their adequacy in terms of policy formulation and development.

The research took into account the accepted standards of good policy formulation to provide perspective and contextualise the study, and delineated educational challenges for the sector. The following theoretical frameworks guided the study: a constructivist approach in interpreting and evaluating the role of school libraries within an education system based in constructivist principles, the traditional policy model to evaluate policy formulation and design, and a social constructionist view of policy in the interpreting of policy development and implementation. The epistemological basis for the main methodology, the Delphi technique, was social constructivism.

The research design comprised two phases. Qualitative data collected from the Delphi panel's expert opinion were interpreted to analyse the policy document critically and assess its implementation strategy. To a lesser extent this article reports on the second phase, the quantitative data from an analysis of existing surveys and reports which provided an overview of the current state of school library provisioning in KwaZulu-Natal. School library models already being implemented in the province were evaluated against this background.

The research results provide guidelines for reviewing and refining the provincial policy intervention and brought to the fore several issues that need to be resolved to facilitate school library development in South Africa. Recommendations are made concerning these guidelines.
\end{abstract}

Keywords: School library policy; school library models; policy development and implementation; Delphi technique; KwaZulu-Natal

\section{Introduction and background}

This research was undertaken to analyse and critically assess the adequacy of the KwaZulu-Natal School Library Policy and its implementation strategy and to test the policy's feasibility for implementation in the province of KwaZulu-Natal $(K Z N)$. This article reports on a larger study which was undertaken as doctoral research (Du Toit 2008) and provides the base research overview for two articles which are planned to follow this one. A fourth article has already been written and published at the request of one of the Delphi panellists from the study, in an Australian journal (Du Toit 2009).

\subsection{Research setting}

\section{School library provisioning}

Inequalities in school library provisioning under the former pre-1994 education departments resulted in widespread lack of facilities, inadequate resources, and a lack of trained personnel in the majority of schools. The disparities were further aggravated by the fact that there was no legislation forcing education departments to provide school libraries and establish library standards. However, the implementation of Curriculum 2005 in 1998 (South Africa. Department of Education. 1999a) was seen as a turning point in South Africa's educational history in many ways and represented a new paradigm in education. It was anticipated that the outcomes-based curriculum with its concepts of integration and lifelong

I. PhD candidate, University of KwaZulu-Natal. Coordinator: Research and Development, Mobile Library Project, South African Primary Education Support Initiative (SAPESI).

2. Professor, Information Studies Programme, School of Social Sciences, College of Humanities, University of KwaZulu-Natal, Pietermaritzburg, South Africa. 
learning, as part of a new approach to education, would transform the legacy of the past and provide equal access to education for all learners.

The school library sector perceived the focus on information literacy and lifelong learning in an outcomes-based teaching methodology as critically important elements underpinning the teaching and learning environment offered by school libraries. The sector assumed that these views would be similarly endorsed by national guidelines and policy which, in turn, would structure, focus and synchronise interventions at national, provincial and school level. However, school libraries have thus far been largely ignored in education reform strategies and the onus is on provincial education departments to establish and develop school library services.

Service delivery background in KwaZulu-Natal

KwaZulu-Natal schools vary in size from small farm schools with one or two staff members to schools with more than 2500 learners and 70 staff members. The demographic and socio-economic environments present a major stumbling block to the provision of education in the province. The learning environment is compromised by the challenges of rural education such as a lack of running water, poor sanitation, inadequate access to electricity, poor infrastructure and transport problems. In many schools the language of instruction is seldom spoken beyond the classroom. Critical health issues such as malaria, bilharzia, and the high prevalence of HIV and AIDS have resulted in a decline in teacher numbers, a loss of expertise, and an increase in the numbers of orphans and out-of-school youths. In the classroom these conditions have translated into poor concentration, absenteeism, and lack of motivation for teachers and learners alike (Bot, Wilson and Dove 2000; EduAction 2004).

School library services in KwaZulu-Natal have to be conceptualised and implemented against this background and, moreover, without the support of national policies or guidelines. In 2002 the Directorate Education Library, Information and Technology Services (ELITS), responsible for school library services in KwaZulu-Natal's Department of Education, argued that it could no longer plan and deliver appropriate services in a vacuum.

The directorate developed a provincial school library policy based on the then national policy draft initiatives. The KZN School Library Policy (KwaZulu-Natal. Department of Education and Culture 2003) promotes, among other things, three school library models as well as a whole-school information literacy policy. The policy's vision takes into account that such a policy at school level will inform, and be informed, by all other aspects of policy and planning. The policy document 'acknowledges the shared responsibility of the teacher, and the truth that information literacy requires a close partnership between the school librarian and the teacher' (De Jager, Nassimbeni and Underwood 2007: 143). The implementation strategy envisages an annual rollout of a starter collection to I 000 schools, which was to start in 2005. However, the annual funding allocation for the project has not increased and fewer schools have been resourced (KwaZulu-Natal. Department of Education 2007b). The implementation plan had to be adapted to reflect this backlog. This sort of situation arises when national priorities have to be factored into financial planning at provincial level without the support of conditional grants from the national department. A change of management in the ELITS Directorate in 2009 also brought about a different focus and policy implementation was reviewed accordingly.

\subsection{Research objectives}

The specific objectives of the research are described in some detail in Du Toit (2008). A succinct summary of these is given below for space reasons. The objectives of the study were to:

- Analyse and critically assess the KwaZulu-Natal School Library Policy document and its implementation strategy by using the Delphi technique as the main methodology for the research. Cohen, Manion and Morrison (2000: 237-238) perceive the Delphi method as the written partner to the Nominal Group Technique 3 in that data are gathered from the participants responding to a series of questions and statements in writing, but with the advantage that the participants are not required to meet together as a group. The researcher collects written responses, collating them into clusters of issues and responses. The analysis is passed back to the respondents for comment, further discussion and identification of issues, responses, and priorities. Respondents are asked to respond to the group response, and can agree or indicate more substantial disagreement. By feeding the group response back to the participants there is a general progression in the technique which allows the polarisation of responses, and thus a clear identification of areas of consensus and dissension.

- Accurately assess the present school library provisioning in the province and identify the most suitable existing models that are already being implemented in KwaZulu-Natal schools by analysing secondary data from available surveys and

3. The Nominal Group Technique is a face-to-face group judgment technique in which participants generate silently, in writing, responses to a given problem. The responses are collected and posted (but not identified by author) for others to view. Through group discussion the responses are clarified and further iterations may follow until a final set of responses is established (Cohen, Manion and Morrison 2000: 237-8). 
reports.

- Test the appropriateness of the provincial policy against the results obtained in the proposed research programme.

- Determine the practical implementation problems that may necessitate policy revision, and evaluate these against the expert opinions offered by the Delphi panel in their responses.

- Suggest possible changes to the policy and propose further implementation strategies to address the needs/problems identified.

- Assess the budget and human resource development implications for the province.

The research questions in bullets two and three will be addressed in more depth in the subsequent articles but are reflected here as they were part of the original study which this article describes.

\subsection{Research questions}

The research was guided by the following questions which mirror the objectives above:

I. What are the key elements of the provincial policy and how adequate are they in terms of policy formulation and development?

2. How adequate is the provincial implementation strategy?

3. What are the practical implementation problems that need to be addressed with regard to the provincial policy?

4. Has the best strategy for the implementation of the provincial policy been identified and can it be successfully implemented?

5. Will the implementation strategy enable ELITS to implement equity and redress past imbalances?

6. Which are the most suitable school library models for implementation in the province? Are the models included in the policy adequate to address the diverse schools or are there alternative models that should have been included?

7. What is an accurate assessment of the present school library provisioning in the province according to the secondary data?

8. What key strategies did experts in the field identify through the use of the Delphi Method, and was the researcher able to refine the responses until consensus was reached?

9. Does the policy include the needed foci identified in the study, and if not, what can be recommended?

10.Does the policy need revision to include recommendations made by the Delphi panel?

I I. Have any topics for future study been identified?

\section{Theoretical framework and literature review}

The study was guided by a constructivist approach in interpreting and evaluating the role of school libraries within an education system based on constructivist principles. In addition the traditional policy model was used to evaluate policy formulation and design, and a social constructionist view of policy was applied in the interpreting of policy development and implementation. The epistemological basis for the main methodology, the Delphi technique, was social constructivism.

\subsection{Theoretical framework}

The research dealt with the following theoretical frameworks:

- Constructivism to evaluate the role of school libraries within a constructivist education system. Constructivist learning theory is at the core of South Africa's Curriculum 2005 and the Revised National Curriculum Statement. School libraries are invaluable tools for providing the necessary resources required for constructing meaning as well as for building on previous learning.

- The traditional policy model to evaluate policy design, as well as the social construction view of policy in order to interpret policy development and implementation. Montviloff (1990: 129) points out that 'policy-making is a continuous process which can never be considered as finished' and although the traditional policy model provides a more structured approach which is useful when the different stages and requirements of policy development are evaluated, the social construction view offers explanations for what Ball (1998: 126) refers to as 'bricolage' and '... a complex process of influence, text production, dissemination, and ultimately, re-creation in context of practice'. The social construction view acknowledges that policy is constructed and sustained by participants, in other words, the policy problem is not a phenomenon on its own and independent of the participants. The question to be asked (Colebatch 2002: 82) is not only how to address the problem, but how the problem is perceived, by whom, and how do they muster support for action by highlighting the problem. According to Terre Blanche, Kelly and Durrheim (2006: 278) social constructionism analyses how signs and images create a certain representation of people and objects that underlie our experiences of them. Social constructionist methods are qualitative, interpretative and have to do with meaning. Where interpretive research concentrates on the subjective understanding and experience of individuals or groups, social constructionist research shows 'how such understanding and experiences are derived from larger discourses'. 
Interpretative approaches see people as the origins 'of their thoughts, feelings and experiences', whereas social constructionism interprets the thoughts, feelings and experiences as 'products of a system of meaning existing at social rather than individual level'. This means that the most obvious difference between an interpretative approach and social constructionism is ontological, in other words a different assumption about the nature of reality to be understood (2006: 278). Terre Blanche et al. (2006: 283) observe, however, that the boundaries between research paradigms are not always clear-cut, and that particularly 'interpretative and constructionist approaches frequently transmute into each other'.

- Social constructivism to understand the epistemological basis for the Delphi technique. Doolittle (1999) cites Bakhtin (1984: I 10) who observes that 'truth is not to be found inside the head of an individual person, it is born between people collectively searching for the truth, in the process of their dialogic action'. This learning theory recognises the individual's contribution to the knowledge construction process and therefore, too, the role and contribution of each Delphi panel member in this process. The Delphi technique was used to structure thinking around the characteristics of good policy as set out in the literature so that consensus or stability could be reached on the suitability of the policy for implementation in the province. The study adopted the approach of the Modified Delphi by using, except for the first part where panellists were asked to contextualise their stance on school library policy, a set of carefully selected items drawn from the literature or other sources instead of an open-ended questionnaire to solicit the first round of information (Custer, Scarcella and Stewart 1999: 2).

\subsection{Literature review}

The literature review outlines Library and Information Services in African as well as South African context, and provides an overview of the policy formulation cycle. The Delphi technique and its growing use as a research method that can be 'applicable to real-life problem solving for librarians' (Howze and Dalrymple 2004: 174) is also discussed.

Library and Information Services: African and South African context

In the 1990s Sturges and Neill (1998: 92) argued that the library services that developed in Africa failed to meet the expectations and match the information needs of African people and advocated that solutions should be sought from within Africa since there is a need

not merely for new approaches to librarianship, but also a creation of parallel, and very different types of information services to complement and partially replace library service... a model that is less formal, less book-oriented, more locally rooted and more precisely targeted at Africa's real and potential information users (1998: 227).

Research (Endra 200I; Rosenberg 200I; Mswazi 2003; Khumalo 2006) has shown that school libraries in Africa are similarly neglected. Studies quote lack of staff, inadequate accommodation, the absence of relevant, adequate stock and no school library budget, ineffective leadership, the exclusion of school librarianship in teacher training curricula, and, especially, the lack of government legislation outlining standards to guide planning and development as the common problems hindering the development of school libraries in Africa. Policy initiatives in Namibia (Marais I996; Namibia. Ministry of Education 2008), Uganda and Swaziland (Mswazi 2003; Khumalo 2006) have yet to be approved. The consensus is that school libraries are marginal in terms of their impact on the teaching-learning process (Sturges and Neill 1998, Rosenberg 200I). One of the biggest problems is the fact that librarians and teachers are not convinced themselves about the importance of libraries, and teachers often persist in using the rigid and sterile teaching methods which they themselves experienced as children (Zinn 20I2).

The school library sector in South Africa is affected in a similar way. The 2008 National Reading Strategy (South Africa. Department of Education 2008) cites the Monitoring Learning Achievement Survey of 1999 which surveyed 25145 schools nationally and found that $22 \mathrm{IOI}$ had no space for a library, 3388 had space but no books, and only I 8 I 7 (just over 7\%) had library space that was stocked with books (South Africa. Department of Education/UNESCO/UNICEF 1999).

Hart (2002: 6I) reasons that an explanation for the weak position of school libraries in the South African school system can be found by turning to theories of learning and teaching. School librarians might interpret the implications of the new outcomes based curriculum as good news, yet this assumes two things: 'that educators understand what a school library is and what its programme aims at; and secondly it assumes that the concepts fundamental to Curriculum 2005 like constructivist learning approaches - are understood'.

Policy standardises provisioning and promotes focussed intervention. Where school library statutes are embedded in education legislation, often within curriculum reform initiatives, they are viewed as educational tools and framed within an educational context, and substantive school library development has resulted in these countries (Knuth 1995). 
Curriculum 2005 offered such an opportunity in South Africa, but the opportunity has not been exploited. Researchers (Le Roux 2002; Karlsson 2003; Zinn 2006; Hart and Zinn 2007) agree with Knuth's (1995: 290) view that 'effective [school library] policy may push development forward [and] non-existent or poorly devised policy hinder development at every phase from conceptualisation, planning, implementation through qualitative improvement efforts'. In many instances school library policy development in South Africa seems to be a series of missed opportunities and even though the process has been ongoing since 1997 no policy has been formally approved as yet. However, in 2012 the Department Basic Education published National Guidelines for School Library and Information Services (South Africa. Department Basic Education 20I2). This initiative may well promote the development of school library services if it is underpinned by a well-developed implementation guide.

The Delphi technique and Library and Information Services (LIS) research

Delphi is growing in popularity as a research methodology in LIS and in South African LIS where Stilwell (2007) applied it in a forecasting exercise. Howze and Dalrymple (2004: 174) view it as an effective way of building consensus without all the disadvantages normally associated with meetings. One of the earliest reviews of the use of Delphi in librarianship was in an article by Fischer (1978). In 1972 Wennerberg (1972: 242) reported on a study conducted by the Swedish Administration for Administrative Development, where a Delphi conducted over three rounds was used 'to reduce uncertainty about future events in the field of information and documentation and to identify relevant alternatives of action'.

According to a May 2003 scan of dissertations, the popularity of the Delphi technique as a research method in LIS can be attributed to the fact that reaching consensus has become such a lengthy process because domineering opinion leaders often influence reticent members in face-to-face meetings (Howze and Dalrymple 2004: 174). Delphi affords the opportunity to seek expert opinion to solve a problem, and incorporates the opinion of all participants which is an additive to any group process. This 2003 search of Dissertation Abstracts, on the term 'Delphi study' and limited to title searching, yielded 797 studies, of which 767 were doctoral dissertations that included 15 studies in library science, of which 14 were doctoral dissertations (2004: 176).

Delphi in LIS has most frequently been applied to forecast trends and events, and to reach consensus on policies or issues. The following are some examples where Delphi was used to study issues in librarianship:

- Web site selection (Green 2000),

- future developments of electronic journals (Keller 200I),

- the future of the library and information science profession (Baruchson-Arbib and Bronstein 2002),

- factors influencing question routing and assignments (Pomerantz, Nicholson and Lankes 2003),

- the future of library as place (Ludwig and Starr 2005).

\section{Methodology}

\subsection{Phase one: Delphi technique}

The Delphi technique was used as the main methodology for the critical analysis of the policy and its implementation strategy and to structure thinking around the characteristics of good policy as set out in the literature.

Firstly in phase one of the research the qualitative data collected from the Delphi panel's expert opinion and responses were interpreted to analyse the policy document critically and to assess its implementation strategy. Practical implementation problems were identified, as well as gaps in the policy that might necessitate revision. Secondly, in phase two, quantitative data from an analysis of existing surveys, questionnaires and reports provided an overview of the current state of school library provisioning in KwaZulu-Natal province, and the school library models already being implemented in the province were evaluated against this background. An analysis of the data from these surveys enabled the researcher to compare the findings from the literature, the Delphi exercise, and the surveys and reports in order to answer the research questions. In this way methodological triangulation was used to enhance the validity of the data collected. For these reasons the findings could tentatively be applied in other similar contexts.

The framework for specific issues such as panel identification and expertise, questionnaire development, pre-testing and data-collection, consensus and analysis was developed by drawing on other Delphi studies identified in the literature search. Seven key studies in the fields of LIS, Education, and Health were used throughout the study for illustrative purposes when methodological issues arose and choices had to be made. The studies were drawn from these disciplines since the research is placed in the LIS and Education disciplines, and moreover the Health Sciences offered a variety of research papers on Delphi as a research method and its use in issues related to medical libraries. The following criteria were used for inclusion of the seven studies and proved to be sufficiently comprehensive to offer insight and a 
comprehensive overview of the key issues considered:

- Currency of the research - published after 1999,

- Reporting on the research itself,

- Discipline in which research was undertaken (LIS, Education, Health Sciences),

- Type of Delphi utilised,

- Published in English.

The main concern in the selection of the Delphi panel for this study was to capture relevant expertise and at the same time ensure representativeness in the sampling, thus, although the selection of panellists was tailored to the issue they were selected from various backgrounds within the subject under investigation. The expertise of the panellists was identified in terms of a review of the literature, personal observation, conference presentations, their being positional leaders, and by virtue of their practical experience in the field or their first-hand experience of the issue.

A single panel of expertise was formed and five of the seven invited panellists completed all the questionnaires. Results from a study by Akins, Tolson and Cole (2005) indicate that 'the response characteristics of a small expert panel in a welldefined knowledge area are stable in light of augmented sampling'. This finding is particularly important for conducting Delphi surveys in knowledge or practice fields where the total number of qualifying knowledgeable individuals is limited. They conclude that reliable outcomes can be obtained with a panel of a relatively small number of Delphi experts, and that a small expert panel from a limited field of study 'may be used with confidence'.

The Delphi was conducted in three rounds. A semi-structured approach was adopted for the first round since a substantial amount of information is available in the policy literature and it was thought important that the data should inform the critical analysis of the policy document and its feasibility for implementation. The questionnaire consisted of three sections, the first part focussed on the conceptual framework of the panellists, the second part identified the key elements of the provincial policy and their adequacy in terms of policy formulation and development, and the last section considered the adequacy of the provincial implementation plan. The questions were unstructured and panel members were encouraged at all stages of the questionnaire to add additional comment.

For the second round of the Delphi the first round responses from the panellists were analysed and added to the questions, thus introducing new ideas and offering the panel members the opportunity to respond to comment offered and to revise their initial response should they wish to do so. Content analysis was used to categorise comment regarding the panellists' approach to policy in school library context into six groupings. Further comment was requested and ratings/rankings of issues from the first round were included for comment and agreement or disagreement.

The third round questionnaire included only the responses from the second round that required further consideration or clarification and issues on which consensus had been reached were excluded.

The degree of consensus reached indicated that three rounds had been adequate in order to gather the necessary data. This number of rounds is in line with research findings quoted by Hasson, Keeney and McKenna (2000: $10 \mathrm{II}$ ).

\subsection{Phase two: surveys as secondary data}

The other focus area of the research, an analysis of the suitability of the provincial school library policy for implementation in the province, required an accurate assessment of the current status of school library provisioning in KwaZulu-Natal, including school library models that were already being implemented in the province in order to test the appropriateness of the provincial policy, determine practical implementation problems and suggest changes to the policy. This assessment was based on an analysis of the following secondary data:

- The results of the 2004 ELITS School Library Audit (KwaZulu-Natal. Department of Education 2004), and the 1999 HSRC's South African School Library Survey in KwaZulu-Natal (South Africa. Department of Education 1999b). These results were compared in order to put the provincial situation in perspective and to comment on changes and possible development and growth since the 1999 survey. The 2004 ELITS School Library Audit (KwaZulu-Natal. Department of Education 2004) was conducted to provide baseline data with which to inform decision-making and planning within the directorate. The response rate of $84 \%$ (5 156 of the 6129 schools) was sufficiently significant to provide a representative picture of library facilities, utilisation, management, and supporting infrastructure in all districts of KwaZulu-Natal.

- A report of site visits by ELITS personnel to 60 schools to evaluate the implementation of the School Library Development Project ${ }^{4}$ (SLDP) by way of a structured interview and the use of an interview schedule (KwaZulu-Natal.

4. The SLDP is the provisioning programme whereby schools are given starter collections according to the provisions of the KwaZuluNatal School Library Policy's implementation strategy (KwaZulu-Natal. Department of Education and Culture 2003: II). 
Department of Education 2007b).

- A Risk Management Report, undertaken by the KZN Department of Education Internal Control and Risk Management sub-directorate (KwaZulu-Natal. Department of Education 2007a) in order to evaluate risks to ELITS' service delivery. This report was used to corroborate some of the findings.

\section{Outcomes of the study}

The interpretation of data is influenced by the theoretical framework of the project as well as the intellectual bias and experience of the researcher (Bertram 2004: 154). Policy is value driven and it is important to be aware of the values or perspectives with which panellists approach the subject when the data are interpreted. Thus it was necessary to ensure that the value judgments or conceptual framework emerging from the responses of the panel member in the first section of the questionnaire related closely to the conceptual framework underpinning the research.

\subsection{Conceptual framework}

The Delphi panel put forward the following beliefs which were linked to the conceptual framework underpinning the research:

- Credible policy needs to be authorised at national and provincial level in order to provide guidelines for and anticipate outcomes of implementation, in other words to guide change. This type of focussed intervention has resulted in the accelerated development in school libraries in other countries.

- Policy without an implementation plan remains a statement of intent. The implementation plan tests the appropriateness of the intervention.

- School libraries are instruments of redress and equity, and have the potential to contribute to educational transformation. An absence of equitable library provisioning, including information and communication technology (ICT), will widen the gap between well-resourced and under-resourced schools.

- Policy alone will not bring transformation, but by involving stakeholders at all levels during the policy process one builds a sense of ownership and responsibility. This involvement will ensure that policy options take into account educational practice on the ground.

- Training is a crucial ingredient in successful school library development. It will bring about and entrench new perspectives and promote holistic insight into the school library's role as a facilitator of reading and information literacy skills, and the construction of knowledge.

The study demonstrated in both its literature review and the interpretation of its findings that all the above elements are inextricably linked to the establishment, development and sustainability of successful school library services and programmes.

\subsection{Research findings}

Research questions reviewed the representativity of the policy task team and the experience they brought to the policy development process, as well as the importance of policy ownership. The adequacy of the policy, the implementation strategy, and the school library models were evaluated and the practical implementation problems identified. Consideration was given to the present state of school library provisioning in the province and the likelihood of the policy achieving equity and redress in this sector. The chosen methodologies and the data generated by them indicated that the policy document and its implementation strategy met, to a large extent, the standards of good policy-making.

Practical strategies for, and solutions to, the challenges of policy implementation in the province were generated. The research results provided sound guidelines for reviewing the policy and the implementation strategy and for developing a more comprehensive strategy for policy implementation. This strategy would in turn refine and refocus the provincial policy intervention.

The results from the following three research questions best summarise the findings and indicate the way forward.

\subsection{Key strategies identified and agreed upon}

On a practical level the Delphi panel translated their beliefs into the following strategies:

- The school library that is set up should meet the needs of the school, its teachers and learners. In order to provide such a service, space is needed, as well as a teacher-librarian, appropriate resources and access to the facility and the resources. The availability of these requirements ensures optimum intervention and benefit, especially if the teacherlibrarian is qualified. The library provisioning does not have to be a one-size fits all. Different models, based on the realities on the ground, experience and financial constraints, and chosen according to circumstances can provide some measure of library access to all schools. Such a service, even if it is a basic modest service, is a start towards achieving equity and better than non-delivery. School libraries create a learning environment that supports reading, teaching and 
learning, extends the curriculum, and provides an indispensable component of education provisioning.

- Reading underpins school performance, and all the benefits of reading need to be emphasised. The importance of reading in both home language and second language should be stressed, since reading develops better second language skills than formal training alone. Panellists suggested that ELITS should consult with industry/publishers to at least try to ensure that the needed resources are being produced within the country.

- The school library supports the social and cultural environment of the school. This strategy emphasises the library's role in social inclusion, the acquisition of appropriate resources to reflect the different cultures, and promotes an understanding of cultural diversity.

- The role of ICT in the school library context needs to be expanded since it is a tool that can, despite the problems experienced with implementation in the present educational background, leapfrog historical disadvantages. The information skills necessary can be acquired and transferred to the ICT environment when it becomes available, although ICT information seeking may require different methods too. The artificial disjuncture between the eeducation sector and the school library sector holds ICT implementation back and ways to promote cooperation should be found.

- Training and ongoing professional development are vital components of a successful school library development programme and crucial to the achievement of the paradigm shift required by outcomes-based education. This development includes pre- and in-service training at all levels since the whole school should be involved from management level down to each learning area teacher. All teachers need to be confident in integrating resources in their teaching programme, promoting and nurturing reading, and assisting learners to develop information literacy skills through critical thinking. This type of learning programme requires, from the teacher's side, both innovative thinking and the innovative use of all available resources. The panel suggested that local fora may assist on a voluntary basis in this respect. Continual professional development should be put in place for subject advisors, as well as followup on this training (by spending some time in the field). The Delphi panel proposed that the lack of capacity (or training, or interest, or all three) should be addressed rather than the implementation strategy adapted since the policy document has been endorsed by the provincial Minister of Education. They expressed concern about the human resources dimensions of this (and other) policy initiative(s) and the level of skills required. To overcome this potential barrier, capacity at school level would have to be increased by utilising funding made available under the KZN Department of Education's Skills Development programme.

- Arguing for qualified staff and lobbying for the creation of posts for teacher-librarians is vital as demand will ensure supply once posts are available. A full-time teacher-librarian does not guarantee that more reading will take place, but the panel observed that there would be something wrong if this did not happen. They conceded that unqualified, motivated staff could also run excellent programmes and suggested that personal qualities such as enthusiasm, motivation and insight be taken into account when appointments are made.

- Policy advocacy, as well as continuous lobbying for human resources and an increased budget to shorten the implementation period, is an important factor in ensuring successful policy implementation and sustaining motivation and patience among implementers and those who benefit from the policy roll-out alike. This extension of the implementation timeframe has been one of the constraints the policy grappled with, and the fact that the budget allocation has remained the same since the first year of implementation has aggravated the problem. The panel suggested that the school library budget should be ring-fenced to ensure its continued allocation.

- A mechanism should be put in place to monitor implementation and provide a reality check against which implementation can be measured and adapted if necessary.

- Clear and open communication lines with district staff where implementation takes place are necessary ingredients. Optimum communication will enable district functions to be better delineated and reporting lines well-structured in order to prevent disjunction between head office, districts and schools.

- Visible efforts should be made to encourage ownership of the policy. The school's readiness to develop and sustain a library, and obtaining buy-in, understanding and cooperation of all role players are aspects that ought to be better covered in training programmes.

As far as policy is concerned, the panel had definite views regarding the characteristics of good policy. They identified strategies and proposed compelling and practical tools to enhance policy implementation and impact. Apart from upholding the values of the Constitution and the Bill of Rights, policy should address inequalities and contribute to transformation. Good policy acknowledges and delineates policy problems clearly, and since the School Library Policy is embedded in education it should take into account educational frameworks such as outcomes-based teaching and learning. Policy constraints ought to be addressed and accommodated in such a way that the policy will make allowances for new developments and anticipated change. Nevertheless, the panel cautioned that lesser services should not be accepted as adequate. Equity and redress should always be kept in mind even if it takes time to achieve them.

SA Jnl Libs \& Info Sci 2012, 78(2) 
The Delphi panel suggested that specific measures be put in place to take the policy process forward successfully. These were the developing and disseminating of supporting documentation to extend the policy by giving details and practical, research-based examples, as well as clear procedures to disseminate information and invite feedback and discussion.

Some of the strategies put forward in the research can be addressed through policy intervention, others are more concerned with managing challenges in the educational environment and with service delivery and cannot be fully dealt with in a policy document. Nevertheless, policy offers valid guidelines on how to manage problems and change.

\subsubsection{Policy foci}

The Delphi panel agreed that the policy did include the necessary foci although not adequately in all instances. Although panellists did not think that the content of the policy needed to change, they put forward suggestions to improve certain aspects that in their view were not adequately covered. These suggestions are included in the recommendations for policy revision under 4.2.3.

The foci, identified by the panel, broadly centred on adequate school library models so that schools could adopt a library model suitable to their needs, and suitably trained staff to provide access to resources in order to inculcate reading and information literacy skills in the school. The role of the school library in outcomes-based education and the role of ICT in school libraries were both emphasised, as well as training for capacity building and to promote awareness of the policy.

The strategies and foci that the panel members identified outlined issues that, according to the panellists, should be addressed in policy revision. These issues, as well as findings from the other research questions are combined below in a comprehensive list of recommendations for policy review.

\subsubsection{Recommendations for policy revision}

Montviloff (1990: 129) rightly observed that policy-making is a continuous process that can never be considered as finished. Though the Delphi panel advised that the policy should be kept clear and simple the following issues were identified and recommendations for policy revision put forward:

- The policy task team should include representation from public libraries, public/community libraries, and parents should be brought in at some stage of the revision of the document. This suggestion is appropriate especially if viewed in light of the Memorandum of Understanding of the provincial Department of Education to be signed with the Department of Arts, Culture and Tourism, and the observation in the Risk Management Report that school governing bodies and parents should be made aware of the importance of the library and the school's responsibility to allocate a budget to the library.

- The underlying problems need to be articulated in one place in the document and/or its annexures. These problems are lack of access to resources, and lack of insight and knowledge regarding the importance of information skills and reading in coping with learning requirements.

- The major causes of the problems need to be explicitly linked to a problem statement to highlight the school library's role and contribution to the educational experience.

- The purpose and objectives of the policy need to include staffing, reading and literacy.

- The role of the school library in contributing to lifelong education should be addressed more specifically.

- The reference to the resuscitation of libraries needs to be clarified, and the nature of the collections in these instances defined.

- The central school library model in a revised policy might, and should, be sold more strongly as a learning resource centre that integrates a computer room and the traditional library.

- The role of ICTs in school libraries should be emphasised. The lack of computer use for educational purposes was highlighted in both the HSRC Survey and the School Library Audit.

- The financial implications of, for example, a shortage of space need to be highlighted in order to address inadequacies. As a panelist commented - 'otherwise where's the redress?'

- Mention of collection building that will reflect and endorse the learners' cultural diversity is needed to draw attention to such diversity.

- Social inclusion needs to be given more prominence in the document.

- Guidelines instead of quantitative standards are likely to prove more practical in achieving school library development.

- Plans for getting the support and buy-in of schools were not adequately covered in the policy document. A great deal of consultation should take place before implementation and this did not appear to have been the case. The importance of this awareness raising and consultation process has been highlighted by the SLDP Evaluation Report (KwaZuluNatal. Department of Education 2007b) as well as the Risk Analysis Report (KwaZulu-Natal. Department of Education 2007a). 
The panellists suggested that some of the problems identified by this research could be addressed in a series of supporting documents to expand upon, support, and extend the scope of the policy. Other suggestions include a separate document drawing on international research and practice on the ground, and curriculum support documents to detail how the vision would be achieved to add weight to the policy. This kind of supplementary documentation would assist policy implementers as a panelist stated 'to bring the vision to fruition.'

The cluster model (a well-resourced library, supported by a provincial service and shared by smallish schools geographically close, or housed at a local community/public library for the use of the surrounding cluster of schools) would require careful planning to work successfully. The progression from this and the classroom model to a central school library needs to be explained and spelled out (in the form of case studies in an addendum), and the factors which are likely to bring about the transition identified. The guidelines developed since the formulation of the School Library Policy to outline ELITS' mandate regarding reading, Education Centres, and ICT in school libraries, should be briefly introduced in a revised policy to present a holistic overview of the interventions in the province.

Most of the panel members agreed that no specific changes were needed to the implementation strategy, but that the strategy could be regularly reviewed and changes (such as changed timelines) communicated to all concerned: policy implementation as a panelist stated 'should be given time to show strengths and weaknesses before reviewing.' The panel thought that a strategy securing the understanding and cooperation of school management and staff for the implementation of the policy would improve the policy's implementation strategy.

The strategies identified by the Delphi panel pinpointed policy areas that need strengthening and offered realistic, well-considered suggestions based on expert opinion and a depth of relevant experience to take the policy process forward.

\section{Conclusion and recommendations}

In keeping with interpretative research, recommendations are made and ideas put forward for future research.

Recommendations for further research include the following:

- Follow-up research on policy implementation is required to evaluate the implementation of the KZN School Library Policy taking into account new role players such as district education centres.

- The teachers' and principals' perceptions of the role of the school library and their levels of awareness need to be researched and built upon in the local context. This research would enable the development of strategies that could lead to the paradigm shift required to implement an outcomes-based approach to teaching and learning as identified in this study.

- The particular information needs of learners in rural areas have to be identified in order to address rural educational challenges and to focus appropriate intervention where most needed. This research can include rural communities since the data generated will be useful for the proposed public library/school library collaborative intervention programme between school and public libraries in KwaZulu-Natal (Nzimande 2008).

- The mobile library as an intervention project to bring resources to schools in rural areas.

- Research on school library models in South Africa/KwaZulu-Natal could determine accurately the benefits of specific models in specific local contexts and offer practical guidelines for the development and implementation of these models. This research would supplement a study undertaken by Nzimande on school clustering in the Nkandla area of KwaZuluNatal (Nzimande 2007; Nzimande and Stilwell 2008).

- Measuring the success of various types and approaches to training as an intervention strategy in school library development and utilisation to offer guidelines on the most effective training programmes and at the same time provide empirical evidence of successful intervention strategies.

- The impact of the Advanced Certificate in Education (School Library Development and Management) programme on school library development in schools in KwaZulu-Natal where certificate holders teach.

- In-depth studies on the impact of school libraries on learner achievement in KwaZulu-Natal are urgently needed. Local impact studies can support the sector in lobbying for infrastructure, funding, and posts for teacher-librarians.

- The role of ICT and the internet in information seeking. Information literacy skills that will enable learners to use technology as a learning tool will promote redress and provide equal access to resources especially in environments where learners do not have access to these resources in their homes. Research is needed to determine whether information skills acquired in school library context can be successfully transferred to an ICT environment when the technology becomes available.

- The National Department of Education's vision of school libraries and information literacy, an overview similar to Van Audenhove's (2003) analysis of South Africa's vision of the information society based on political rhetoric and policy initiatives should be captured. This research could provide insight into agenda-setting strategies and offer explanations for the national department's seeming reluctance to finalise policy for school libraries. 
- Reading intervention assessment in project schools in KwaZulu-Natal to assess the success of the newly introduced reading policy guidelines is being undertaken by MacGarry (2008) and could be built on further.

The study has brought to the fore several issues that need to be resolved to facilitate school library development in South Africa:

- The lack of support and overall direction from the national Department of Education as manifested in its reluctance to finalise national school library policy. Informal sources report that school library guidelines will be published shortly.

- The importance of ICT as a learning tool to provide to all learners equal access to information.

- The general lack of human, physical and financial resources required to achieve satisfactory implementation of the KZN School Library Policy.

- Partnerships and innovative service delivery solutions are required to address the backlog in school library provisioning, even if this intervention takes place initially only on a small scale.

\section{References}

Akins, R.B., Tolson, H. and Cole, B.R. 2005. Stability of response characteristics of a Delphi panel: application of bootstrap data expansion. BMC Medical Research Methodology, 5:37. http://www.biomedcentral.com//47/-2288/5/37 (Accessed 7 February 2008).

Bakhtin, M.M. 1984. Problem of Dostoevsky's poetics. Minneapolis, MN: University of Minnesota Press.

Ball, S.J. 1998. Big policies / small world: an introduction to international perspectives in education policy. Comparative Education, 34(2): I19-130.

Baruchson-Arbib, S. and Bronstein, J. 2002. A view to the future of the Library and Information Science profession: a Delphi study. Journal of the American Society for Information Science and Technology, 53(5):397-408.

Bertram, C. 2004. Understanding research: an introduction to reading research. $2^{\text {nd }}$ ed. Pietermaritzburg: School of Education. Training and Development, University of KwaZulu-Natal.

Bot, M., Wilson, D. and Dove, S. 2000. The education atlas of South Africa. Houghton: The Education Foundation.

Cohen, L, Manion L and Morrison, K. 2000. Research methods in education. $5^{\text {th }}$ ed. London: RoutledgeFalmer.

Colebatch, H. K. 2002. Policy. $2^{\text {nd }}$ ed. Buckingham: Open University Press.

Custer, R.L., Scarcella, J.A. and Stewart, R.B. 1999. The modified Delphi technique: a rotational model. Journal of Vocational and Technical Education, I5(2). http://scholar.lib.vt.edu/ejournals/JVTE/v/5n2/custer.html (Accessed 3 December 2006).

De Jager, K., Nassimbeni, M. and Underwood, P. 2007. Libraries, literacy and learning: retrospect and prospects. In Bothma, T., Underwood, P. and Ngulube, P. (eds). Libraries for the future: progress and development of South African libraries. Pretoria: LIASA. pp. I33-147.

Doolittle, P.E. 1999. Constructivism and online education. Virginia Polytechnic Institute and State University. http:// edpsychserver.ed.vt.edu/workshops/tohe 1999/text/doo2.pdf (Accessed I8 December 2007).

Du Toit, M. 2008. The KwaZulu-Natal school library policy and its feasibility for implementation in the province. PhD thesis. Pietermaritzburg: University of KwaZulu-Natal.

Du Toit, M. 2009. Policy formulation and practical implementation problems: KwaZulu-Natal school library policy, South Africa. Synergy, 7(2). http://www.slav.vic.edu.au/synergy/

EduAction. 2004. Education statistics in KwaZulu-Natal: 2003. Durban: EduAction.

Endra, C.J. 200I. Public and school libraries in Uganda. In Proceedings of the Pan-African/Pan Arab Conference on School and Public Libraries, EIS-Rabat, Morocco, 19-22 September. IFLA: The Hague.

Fischer, R.G. 1978. The Delphi method: a description, review, and criticism. Journal of Academic Librarianship, 4 (2): $64-70$.

Green, J.W. 2000. Delphi method in web site selection: using the experts. The Reference Librarian, 69/70:299-310.

Hart, G. 2002. The school library and curriculum change in South Africa: contradictions and connections. In Ghost libraries and curriculum 2005. Durban: Department of Education and Culture. ELITS Directorate.

Hart, G. and Zinn, S. 2007. The conundrum of school libraries in South Africa. In Bothma, T., Underwood, P. and Ngulube, P. (eds). Libraries for the future: progress and development of South African libraries. Pretoria: LIASA. pp. 89-I06.

Hasson, F., Keeney, S. and McKenna, H. 2000. Research guidelines for the Delphi survey technique. Journal of Advanced Nursing, 32(4): $1008-1015$.

Howze, P.C. and Dalrymple, C. 2004. Consensus without all the meetings: using the Delphi method to determine course content for library instruction. Reference Services Review, 32(2): I74- 184.

Karlsson, J. 2003. The politics of making a new space for school libraries in South Africa. In Zinn, S., Hart, G. and Howe, E. IASL reports, 2003. School libraries: breaking down barriers. Selected papers from the $32^{\text {nd }}$ annual conference of the International Association of School Librarianship and the $7^{\text {th }}$ International Forum on Research in School Librarianship. Durban: IASL. Pp. I-9.

Keller, A. 200I. Future developments of electronic journals: a Delphi study. The Electronic Library, 19(6):383-396.

Khumalo, L.J. 2006. Use and non-use of selected senior secondary school libraries in Manzini, Swaziland. MIS thesis. Pietermaritzburg: University of KwaZulu-Natal.

Knuth, R. 1995. School librarianship and macro-level policy issues: international perspectives. IFLA Journal, 2 I (4):290-298.

KwaZulu-Natal. Department of Education. 2004. Analysis of the 2004 ELITS school library audit. Directorate: Education Library Information and Technology Services. Durban: EduAction.

KwaZulu-Natal. Department of Education. 2007a. Risk management report: Risk and control exercise over Education Library Information and Technology Services: Project number 3/7/2(44-07-08). Pietermaritzburg: Department of Education. 
KwaZulu-Natal. Department of Education. 2007b. School library development project (SLDP): evaluation report July 2007. Compiled by TM Gumede, SH Mbongwe and FK Dubazana. Unpublished report. Directorate: Education Library Information and Technology Services. Pietermaritzburg: Department of Education.

KwaZulu-Natal. Department of Education and Culture. 2003. School library policy. Directorate Education Library Information and Technology Services. Durban: Department of Education and Culture.

Le Roux, S. 2002. School library policy in South Africa: where do we stand? South African Journal of Libraries and Information Science, 68(2): II $12-120$.

Ludwig, L. and Starr, S. 2005. Library as place: results of a Delphi study. Journal of Medical Library Associations, 93(3): 31 5-326.

MacGarry, V. 2008. Personal communication. 2I May.

Marais, A. 1996. Basic information science: bridging the gap in Namibia. In Karlsson, J. (ed.). School learners and libraries. Durban: Education Policy Unit, University of Natal. pp. 53-63.

Montviloff, V. 1990. National information policies: a handbook on the formulation, approval, implementation and operation of a national policy on information. Paris: UNESCO.

Mswazi, P. 2003. Knowledge age school library services in developing countries: a case study. Education Libraries Journal, 46(3): 15-23.

Namibia. Ministry of Education. 2008. Head office directorates: National archives and library services. http://www.mec.gov.na/ ministryOfEducation/nalsHeadOfficeD.htm (Accessed 30 June 2008).

Nzimande, E.S. 2007. An investigation into the awareness and preparedness of Inkandla and Mbazwana school clusters concerning the sharing of information sources. MIS thesis. Pietermaritzburg: University of KwaZulu-Natal.

Nzimande, E.S. 2008. Personal communication. I5 May.

Nzimande, E.S. and Stilwell, C. 2008. Sharing information resources: a study of school clusters from rural KwaZulu-Natal, South Africa. Libri, 58(4): 234-245.

Pomerantz, J., Nicholson, S. and Lankes, R.D. 2003. Digital reference triage: an investigation using the Delphi method into the factors influencing question routing and assignment. The Library Quarterly, 73(2): I03-I 20.

Rosenberg, D. 200I. The sustainability of libraries and resource centres in Africa. In Stilwell, C., Leach, A. and Burton, S. (eds). Knowledge, information and development: an African perspective. Pietermaritzburg: School of Human and Social Studies, University of Natal. pp. I I-24.

South Africa. Department Basic Education. 2012. National guidelines for school library and information services. Pretoria: Department Basic Education.

South Africa. Department of Education. 1999a. Curriculum 2005: towards a theoretical framework. Pretoria: Department of Education.

South Africa. Department of Education. 1999b. South African school library survey 1999: Provincial report: KwaZulu-Natal. Pretoria: Department of Education and Human Sciences Research Council. Photocopied document.

South Africa. Department of Education. 2008. National reading strategy. Pretoria: Department of Education.

South Africa. Department of Education/UNESCO/UNICEF. 1999. Monitoring and learning achievement. Pretoria: Department of Education.

Stilwell, C. 2007. South African LIS futures and the tale of the fisherman's wife: can we predict and create positive change? In Bothma, T., Underwood, P. and P. Ngulube (eds). Libraries for the future: progress and development of South African libraries. Pretoria: LIASA/ Department of Arts and Culture. pp. 199-2I8.

Sturges, $\mathrm{P}$ and Neill, R. 1998. The quiet struggle: information and libraries for the people of Africa. $2^{\text {nd }}$ ed. London: Mansell.

Terre Blanche, M., Kelly, K. and Durrheim, K. 2006. Why qualitative research? In

Terre Blanche, M., Durrheim, K. and Painter, D. (eds). $2^{\text {nd }}$ ed. Research in practice: applied methods for the social sciences. Cape Town: University of Cape Town Press. pp. 272-284.

Van Audenhove, L. 2003. Towards an integrated information society policy in South Africa: an overview of political rhetoric and policy initiatives 1994 - 2000. Cape Town: HSRC Publishers.

Wennerberg, U. 1972. Using the Delphi technique for planning the future of libraries. UNESCO Bulletin for Libraries, 26(5):24246, 252.

Zinn, S. E. 2006. Have trained school librarians made a difference for school libraries in South Africa? Innovation: Journal of Appropriate Librarianship and Information Work in Southern Africa, 33:21-35.

Zinn, S. E. 2012. Information literacy in the classroom: assessing the competency of Western Cape teachers in information literacy education. PhD thesis. Pietermaritzburg: University of KwaZulu-Natal. 